\title{
Techniques of Gastrointestinal Endoscopy-Do We Need to Change Anything?
}

\author{
Prakash Zacharias ${ }^{1}$ Hasim Ahamed \\ ${ }^{1}$ Division of Gastroenterology, Chief of Endoscopy, \\ Lisie Institute of Gastroenterology, Lisie Hospital, \\ Kaloor, Kochi, Kerala, India
}

Address for correspondence Prakash Zacharias, MD, DM, Chief of Endoscopy, Lisie Institute of Gastroenterology, Lisie Hospital, Kaloor, Kochi 682017, Kerala, India (e-mail: prakash.zacharias@gmail.com).

\begin{abstract}
Keywords

- COVID-19

- endoscopy

$-E G D$

Novel coronavirus disease 2019 (COVID-19) has spread to different parts of the world and was declared a pandemic by World Health Organization (WHO). Health care workers are at increased risk of contracting the disease due to their nature of work and close contact with the patients. Staff in endoscopy need to be aware of this risk due to the aerosol-generating nature of procedures and the presence of virus particles in stool samples of infected persons. The risk of asymptomatic patients spreading the disease is also a cause for concern. This article intends to provide guidance and recommendations for techniques and practice of gastrointestinal $(\mathrm{Gl})$ endoscopy to prevent infection in endoscopy unit.
\end{abstract}

\section{Introduction}

The novel corona virus disease 2019 (COVID-19), declared a pandemic by the World Health Organization (WHO), has stretched the health care delivery systems across the world and thrown challenges to each medical specialty. Though the disease affects all age groups, mortality is higher in those above 60 years and comorbid conditions. ${ }^{1}$

Health care workers (HCW) are at increased risk of acquiring infection during care of patients. In Italy, 20\% of responding HCW were infected and some lost their lives to the illness. ${ }^{2,3}$ In one news report from India, an endoscopy technician was among the infected HCW. An endoscopy technician of Indian origin succumbed to illness in UK recently. ${ }^{4}$ However, the source or the route of infection in these patients are not clear.

The mode of transmission suggested for COVID-19 include droplets, person-to-person contact, and airborne spread. With the finding of virus RNA in stool of patients with infection, fecooral transmission is also suggested as a mode of transmission. ${ }^{5}$ Though majority of those infected are symptomatic, some may remain asymptomatic and can still be infective. ${ }^{6,7}$

In India and many other countries, testing for COVID-19 is limited to high-risk groups. As per Indian Council of Medical Research (ICMR), testing is recommended only for those with symptoms, asymptomatic high-risk persons, and direct contacts of a confirmed case. ${ }^{8}$ This would imply that there may be a group of patients, who are asymptomatic and not tested but harboring infection. In this scenario, any person attending a clinic or hospital should be considered a potentially infected patient and precautions taken accordingly.

In compliance with various society guidelines, endoscopy units perform only emergency and urgent cases now. ${ }^{5,9-11}$ However, once the restrictions are withdrawn by the government, pending or postponed procedures would need attention. This would create a situation where the endoscopy units are overwhelmed with patients which may have an occasional asymptomatic infected person. Hence HCW need to be vigilant and work efficiently without compromising the safety of patients and themselves.

\section{Endoscopy Personnel}

During this period of uncertainty, it is prudent that any staff above 60 years and comorbid conditions abstain or minimize their work in endoscopy unit. They may be re assigned duties in other areas. Any staff member with history of contact with COVID-19 or recent international travel should follow the recommended protocol for isolation/quarantine and avoid regular duties. All staff should have a daily check on their physical condition including fever or respiratory symptoms upon which they should follow the institutional or health 
authorities' advices. Recommendations for endoscopy personnel are given in - Table $\mathbf{1}$.

The endoscopy units can consider having scrub suit for all staff. At the end of the day, the scrubs should be changed to regular clothes while leaving the hospital to avoid contamination. It would be advisable to have a shower after a procedure on COVID-19 positive or suspected patient. Having a separate pair of shoes within the endoscopy can also prevent cross contamination. ${ }^{5,10-12}$

Performing an endoscopy procedure requires assistance from various persons including endoscopy assistant/ technician and nurse. The nurse assists the endoscopist in administering sedation and monitoring of patient. In certain countries, the nurse administering the sedation assists in taking biopsies and other procedures too. ${ }^{13}$ In India, there has not been any recommendations so far in this regard. Many endoscopy units have a technician to assist the endoscopist, an assistant to hold the endoscope and a nurse administering the sedation. Pruning the number of assistants is necessary to comply with social distancing of 6 feet in a limited area. Using a bite guard with strap for upper GI endoscopic procedures, Endoscopic ultrasound (EUS) and Endoscopic retrograde cholangiopancreatography (ERCP) can help to reduce an assistant. If the nurse administering sedation is able to handle biopsies, the number of persons in the room can be reduced further. In the event of an emergency, assistance should be available in an ante room. However, this would not be appropriate in a sick patient and patients needing complex endoscopic procedures where dedicated monitoring and expert technical assistance is required. The images acquired during endoscopy are saved for future retrieval and reporting using software. Acquiring images would need the help of a secretary or assistant in certain situations and software. Saving of manpower can be done if the image acquisition can be performed by pressing a foot pedal or endoscope buttons.

A guidance for the minimum no: of endoscopy staff required is given in - Table 2 .

Since, many of these measures are different from the usual practice in endoscopy units, it is imperative that all members of the team are appraised of the changes and each one knows

Table 1 Guidance for personnel in endoscopy

\begin{tabular}{|l|}
\hline $\begin{array}{l}\text { Reassign duties for staff }>60 \text { years of age, co morbid conditions, } \\
\text { and immunosuppression }\end{array}$ \\
\hline Limit the no: of assistants (endoscopy and anesthesia) \\
\hline Maintain distance of 6 feet if possible \\
\hline Assign endoscopy staff including endoscopist to one room daily \\
\hline Perform procedures by consultants or faculty \\
\hline Avoid trainees and fellows \\
\hline Wear appropriate personal protective equipment \\
\hline Perform hand hygiene pre and post procedure \\
\hline Avoid using personal lap tops in the endoscopy room \\
\hline $\begin{array}{l}\text { Minimize the persons using the computer, allocate to one person } \\
\text { daily if feasible }\end{array}$ \\
\hline $\begin{array}{l}\text { Place a disposable transparent sheet over computer keyboard, to } \\
\text { be changed after individual use }\end{array}$ \\
\hline
\end{tabular}

Table 2 Suggested number of endoscopy personnel for procedures

\begin{tabular}{|l|}
\hline Esophagogastroduodenoscopy: 2 (including endoscopist) \\
\hline Therapeutic/complex endoscopic procedures: 3 \\
\hline Colonoscopy: 2 \\
\hline EUS/ERCP under sedation: 3 \\
\hline ERCP under anesthesia: 4 \\
\hline EUS under anesthesia: 4 \\
\hline
\end{tabular}

Abbreviations: EUS, Endoscopic ultrasound; ERCP, Endoscopic retrograde cholangiopancreatography

their role. A daily briefing of the members of the unit and anesthetist prior to the start of each day would improve their compliance.

\section{Preprocedure Assessment and Triage}

Prior to performing endoscopic procedure, a nurse directed preprocedure assessment and triage protocol is recommended which include history of fever, sore throat, respiratory symptoms, recent travel history, contact with an infected person, or stay in a high-risk area. Patients should be stratified as high, intermediate, or low risk based on the triage. ${ }^{14}$

\section{Endoscopy Suite}

The entry to endoscopy suite should be restricted. Relatives of patients should not be allowed into endoscopy room unless it is absolutely necessary. As soon as the patient is brought to the endoscopy room, the pre procedure assessment document should be reviewed to confirm the status of patient. A suggested flow pattern for endoscopy is given in $\boldsymbol{- F i g .} \mathbf{1}$.

All patients should be advised to wear a mask prior to entry into the endoscopy unit. Those patients in intermediate or high-risk category should have a surgical mask which can be removed prior to the procedure. All patients should have their hands cleaned by washing with soap and water or hand rub prior to placement of pulse oximeter probe.

In case of a suspected or known COVID-19 patient, consider doing the procedure at the end of the day, if deferring is not feasible. It would be advisable to do the procedure in a negative pressure room if available, or consider doing the procedure at bedside. ${ }^{12}$ In a scenario where many such patients need procedure, creating an infected pathway separated by noninfected areas can be considered. ${ }^{15}$

\section{Endoscopy Procedures}

Upper GI endoscopy is considered as an aerosol-generating procedure. In a study by Johnston et al, it was shown that there is significant risk of body fluid exposure to endoscopist's face during esophagogastroduodenoscopy (EGD)..$^{16}$ Prior to EGD, patients are administered local anesthetic spray to the throat. However, some patients can have cough and retching during this process producing aerosols which may harbor virus particles. In spite of applying local anesthetic agent, patients may become uncooperative due to throat irritation during 




Fig.1 Suggested work flow pattern in endoscopy room. COVID-19, novel coronavirus disease 2019; IV, intravenous; PPE, personal protective equipment. EUS, endoscopic ultrasound; ERCP, endoscopic retrograde cholangiopancreatography; GA, general anaesthesia; LA, local anesthesia.

procedure leading to cough and retching creating excess secretions and probable aerosolization. ${ }^{17}$ To prevent this, we would advise the use of local anesthetic viscous instead of spray and consider conscious sedation to improve patient cooperation. In addition, using a modified oxygen mask with an opening adequate enough for introducing the endoscope placed over a bite guard may prevent aerosols. ${ }^{18}$

Since COVID-19 RNA has been detected in stools of patients with infection, the colonic effluent and flatus passed during procedure may contain infective viral particles. Hence adequate precautions should be taken while performing these procedures. Placing an absorbable pad or sheet of sufficient length under the buttocks of the patient during colonoscopy would absorb any effluent and prevent spillage to surrounding area. In experimental conditions, severe respiratory syndrome-coronavirus-2 (SARS-CoV-2) has been found to be viable for 3 hours in aerosol to 3 days in various environmental surfaces..$^{19}$ In view of the possibility of spilling of secretions and colonic effluent on environmental surfaces during a procedure, cleaning of the room and environmental surface with a surface disinfectant should be done after each procedure in intermediate- and high-risk patients. In low-risk patients, routine surface cleaning procedure can be followed. ${ }^{14}$

ERCP and EUS are done under anesthesia in many endoscopy units. During these procedures, more persons occupy the room, especially during ERCP, in view of the need for fluoroscopy and anesthesia. The modern fluoroscopy machines are user friendly and it can be operated by endoscopy technician or the endoscopist with some guidance and training. Reducing the anesthesia personnel to two, comprising of anesthetist and technician would optimize the services. As part of pruning of the personnel in endoscopy and reducing the procedure time, it would be advisable to avoid trainees and fellows except in special circumstances. The accessories used during ERCP- and EUS-guided procedures should be disposable, or if reused, should follow institutional policy of cleaning and disinfection. ${ }^{10-12}$ Care should be taken by endoscopy assistants during exchange of guide wires and accessories to prevent aerosols. - Table 3 summarizes the precautions to be taken during endoscopy procedures.

Frequent communication is required between the endoscopist and technician during the procedure to avoid any mishap. Following the procedure, the accessories should be disposed safely. Precleaning of the endoscopes should be done at the bedside after taking appropriate precautions including use of personal protective equipment (PPE).

Table 3 Precautions to be taken during procedure

\begin{tabular}{|l|}
\hline Use tight rubber cap for biopsy channel \\
\hline Limit the no: of biopsies if possible \\
\hline $\begin{array}{l}\text { Exercise caution while withdrawing the accessory from biopsy } \\
\text { channel; Applying suction would be advisable during this process }\end{array}$ \\
\hline Use disposable biopsy forceps \\
\hline Use disposable accessories during ERCP/EUS \\
\hline Handle biopsy specimen with care \\
\hline $\begin{array}{l}\text { Place a disposable absorbable sheet/pad below the buttocks } \\
\text { during colonoscopy and below the face during upper gastrointes- } \\
\text { tinal procedures }\end{array}$ \\
\hline
\end{tabular}

Abbreviations: EUS, Endoscopic ultrasound; ERCP, Endoscopic retrograde cholangiopancreatography 


\section{Postprocedure Management}

All admitted patients undergoing procedure may be shifted to room immediately after recovery. In a COVID-19 positive or suspected patient, allow recovery in the endoscopy room itself or in an isolation area before shifting. ${ }^{12}$ Outpatients should be followed-up telephonically for any new onset fever or respiratory symptoms for 2 weeks.

\section{Conclusion}

Endoscopy personnel are at high risk of COVID-19 infection due to the aerosol-generating procedure and presence of virus particles in the stool. The functioning of the endoscopy unit should be modified in this extraordinary circumstance. Awareness of the route of infection spread and precautions to be taken has to be overemphasized. Screening patients prior to procedure, limiting the number of personnel in endoscopy room, assigning specific roles, empowering the staff with adequate knowledge, modifying techniques, and accessories, use of PPE, performing hand hygiene, and careful handling of endoscope accessories would go a long way in preventing this infection.

\section{Conflict of Interest}

None declared.

\section{References}

1 Rothan HA, Byrareddy SN. The epidemiology and pathogenesis of coronavirus disease (COVID-19) outbreak. J Autoimmun 2020;109:102433

2 Schwartz J, King C-C, Yen M-Y. Protecting health care workers during the COVID-19 coronavirus outbreak -lessons from Taiwan's SARS response. Clin Infect Dis 2020;:ciaa255, (e-pub ahead of print). doi:10.1093/cid/ciaa255

3 COVID-19: protecting health-care workers. Lancet 2020;395(10228):P:922

4 Doctor among 3 test positive for COVID-19 at Max hospital. Available at: https://www.indiatoday.in/india/story/doctortest-positive-covid19-max-hospital-1666632-2020-04-13. Accessed April 24, 2020

5 Lui RN, Wong SH, Sánchez-Luna SA, et al. Overview of guidance for endoscopy during the coronavirus disease 2019 (COVID19) pandemic. J Gastroenterol Hepatol 2020;(e-pub ahead of print). doi:10.1111/jgh.15053

6 Wang Y, Wang Y, Chen Y, Qin Q. Unique epidemiological and clinical features of the emerging 2019 novel coronavirus pneumonia (COVID-19) implicate special control measures. J Med Virol 2020;(e-pub ahead of print) doi:10.1002/jmv.25748

7 Hu Z, Song C, Xu C, Jin G, Chen Y, Xu X, et al. Clinical characteristics of 24 asymptomatic infections with COVID-19 screened among close contacts in Nanjing, China. Sci China Life Sci 2020;63(5):706-711

8 Indian Council of Medical Research, Department of Health Research. Strategy for COVID19 testing in India (Version 4, dated 09/04/2020). Available at https://icmr.nic.in/sites/ default/files/upload_documents/Strategey_for_COVID19_ Test_v4_09042020.pdf. Accessed April 24, 2020

9 Castro Filho EC, Castro R, Fernandes FF, Pereira G, Perazzo H. Gastrointestinal endoscopy during COVID-19 pandemic: an updated review of guidelines and statements from international and national societies. Gastrointest Endosc 2020;(e-pub ahead of print). doi:10.1016/j.gie.2020.03.3854

10 Tse F, Borgaonkar M, Leontiadis GI. COVID-19: advice from the Canadian Association of Gastroenterology for endoscopy facilities, as of March 16, 2020. J Canad Assoc Gastroenterol 2020 doi

11 Philip M, Lakhtakia S, Aggarwal R, Madan K, Saraswat V, Makharia G. Joint guidance from SGEI, ISG and INASL for gastroenterologists and gastrointestinal endoscopists on the prevention, care and management of patients with COVID-19. J Clin Exp Hepatol 2020;(e-pub ahead of print). doi https://doi. org/10.1016/j.jceh.2020.04.001

12 Thompson CC, Shen L, Lee LS. COVID-19 in endoscopy: time to do more? Gastrointest Endosc 2020;:S0016-5107(20)34126-2, (e-pub ahead of print). doi:10.1016/j.gie.2020.03.3848

13 Jain R, Ikenberry SO, Anderson MA, et al; ASGE Standards of Practice Committee. Minimum staffing requirements for the performance of GI endoscopy. Gastrointest Endosc 2010;72(3):469-470

14 Repici A, Maselli R, Colombo M, et al. Coronavirus (COVID-19) outbreak: what the department of endoscopy should know. Gastrointest Endosc 2020;:S0016-5107(20)30245-5, (e-pub ahead of print). doi:10.1016/j.gie.2020.03.019

15 Cortegoso Valdivia P, Le Grazie M, Gaiani F, Decembrino F, De' Angelis GL. Separated pathways in the endoscopy unit for COVID-19 patients. Gastrointest Endosc 2020;:S00165107(20)34119-5, (e-pub ahead of print). doi:10.1016/j. gie.2020.03.3841

16 Johnston ER, Habib-Bein N, Dueker JM, et al. Risk of bacterial exposure to the endoscopist's face during endoscopy. Gastrointest Endosc 2019;89(4):818-824

17 Soetikno R, Teoh AYB, Kaltenbach T, et al. Considerations in performing endoscopy during the COVID-19 pandemic. Gastrointest Endosc 2020;:S0016-5107(20)34033-5, (e-pub ahead of print). doi:10.1016/j.gie.2020.03.3758

18 Marchese M, Capannolo A, Lombardi L, Di Carlo M, Marinangeli F, Fusco P. Use of a modified ventilation mask to avoid aerosolizing spread of droplets for short endoscopic procedures during coronavirus COVID-19 outbreak. Gastrointest Endosc 2020;:S0016-5107(20)34131-6, (e-pub ahead of print). doi:10.1016/j.gie.2020.03.3853

19 van Doremalen N, Bushmaker T, Morris DH, et al. Aerosol and surface stability of SARS-CoV-2 as compared with SARSCoV-1. N Engl J Med 2020;382(16):1564-1567 